\title{
Experimental investigation of dry granular flow impact via both normal and tangential force measurements
}

\author{
Y.-J. JIANG* and Y. ZHAO*
}

\begin{abstract}
The study of granular flow is important for natural hazards such as avalanche and debris flow. In this context, granular flow impact against a retaining wall was investigated through the measurement of both normal and tangential sub-forces. The tangential sub-forces change from positive to negative with respect to the wall in the impact process, which can be classified into two impact states according to the development of the stagnant zone. In the process, interface friction between the granular material and the wall is calculated according to normal and tangential forces and defined as the equivalent interface friction angle, which is observed to vary, and is smaller than the value measured in interface friction tests. The absolute value of the equivalent interface friction angle decreases with slope angle. It was also observed that a reduction in the interface friction angle of the wall has a negligible influence on the impact force calculation, while a reduction in the interface friction angle of the flume base leads to a significant overestimation of the force. These findings should significantly aid the study of granular flow and its applications.
\end{abstract}

KEYWORDS: earth pressure; laboratory tests; retaining walls; soil/structure interaction

ICE Publishing: all rights reserved

\section{NOTATION}

Manuscript received 7 January 2015; first decision 28 January 2015; accepted 9 February 2015.

Published online at www.geotechniqueletters.com on 9 March 2015.

*Institute of Mountain Hazards \& Environment, Chinese Academy of Sciences, Chengdu, China

\section{INTRODUCTION}

Granular flows developed during phenomena such as a landslide or rock avalanche can apply tremendous impact forces on an obstacle in their flow path (Tai et al., 2001; Sovilla et al., 2008; Faug et al., 2011). When a granular flow interacts with a retaining structure such as a retaining wall, a stagnant zone (deposition of granular material) and an inertial layer (flowing layer of granular material) coexist and influence the impact process (Faug et al., 2009; Jiang et al., 2015). Figure 1 illustrates such a case. Depending on the volume of the stagnant zone and the depth of the inertial layer as well as their geometrical relations, the force exerted on a retaining wall can consist of a drag force $F_{\mathrm{d}}$ (Buchholtz \& Pöschel, 1998) and an active or passive earth force $F_{\mathrm{p}}$ (Savage \& Hutter, 1989), which are generated by the inertial layer, while the stagnant zone can generate a gravity- and friction-induced force $\left(F_{\mathrm{gf}}\right)$ (Faug et al., 2011; Jiang \& Towhata, 2013). In the case that a granular flow is fully trapped by the retaining wall (Fig. 1), the resultant force can be expressed as (Jiang et al., 2015)

$$
\begin{aligned}
F & =F_{\mathrm{d}}+F_{\mathrm{p}}+F_{\mathrm{gf}} \\
& =\frac{1}{2} \rho v^{2} C_{\mathrm{d}} h+\frac{1}{2} k_{\mathrm{p}} \rho g h^{2} \cos \alpha+G \frac{\sin \left(\alpha-\delta_{1}\right)}{\cos \left(\delta_{1}+\delta_{2}\right)} \cos \delta_{2}
\end{aligned}
$$

in which

$$
C_{\mathrm{d}}=a \mathrm{Fr}^{-n}=a\left(\frac{v}{(\mathrm{~g} h)^{1 / 2}}\right)^{-n}
$$

and

$$
k_{\mathrm{p}}=\frac{\cos \alpha+\left(\cos ^{2} \alpha-\cos ^{2} \phi\right)^{1 / 2}}{\cos \alpha-\left(\cos ^{2} \alpha-\cos ^{2} \phi\right)^{1 / 2}}
$$

In the above equations, $C_{\mathrm{d}}$ denotes the empirical drag coefficient, which is a function of the Froude number $(\mathrm{Fr})$ and two empirical constants, $a=10 \cdot 8$ and $n=1 \cdot 3$ (Thibert et al., 2008), $\rho$ is the density of granular flow, $v$ is the 


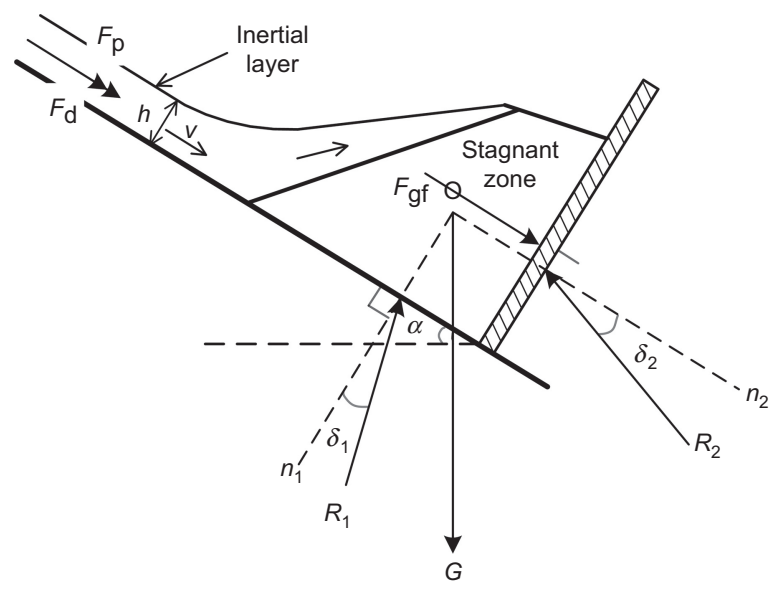

Fig. 1. Schematic illustration of granular flow impact against a retaining wall, in which a part of the granular material is already deposited upstream of the wall to form the stagnant zone, while the layer of flowing granular material continues to impact and flow in the stagnant zone. $R_{1}$ and $R_{2}$ denote the reaction forces on the flume base and the wall, respectively

depth-averaged velocity, $h$ is the flow thickness, $g$ gravitational acceleration, $\alpha$ the slope angle and $\phi$ the dynamic internal friction angle. Further, $G$ denotes the weight of the stagnant zone, $\delta_{1}$ is the interface friction angle of the flume base and $\delta_{2}$ is the interface friction angle of the retaining wall.

In previous studies (Jiang \& Towhata, 2013), only the force normal to the retaining wall surface has been primarily studied, while the influence of the force tangential to the retaining wall has hardly been investigated. This paper thus reports experimental results of granular flow impact studied via measurements of both the normal and tangential forces on a retaining wall. The suitability of equation (1) is also reviewed with a focus on the tangential friction on the retaining wall.

\section{EXPERIMENT}

A type of limestone particle, designated particle 1, was selected for this study. Its appearance and particle size distribution are shown in Fig. 2 and typical particle characteristics are listed in Table 1. The interface friction angle was determined by tilting a board until a cylindrical paper container full of granular material placed on the board started to slide (Pudasaini et al., 2007). Instead of direct measurement of the dynamic internal friction angle,

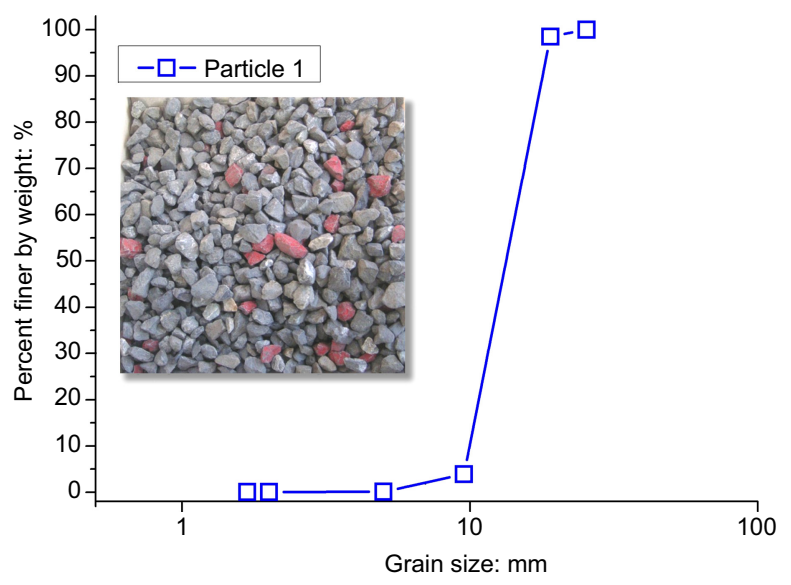

Fig. 2. Particle size distribution of particle 1
Table 1. Physical properties of particle 1

\begin{tabular}{l|c}
\hline Property & Value \\
\hline Minimum dry unit weight, $\gamma_{\min }: \mathrm{kN} / \mathrm{m}^{3}$ & $13 \cdot 5$ \\
Maximum dry unit weight, $\gamma_{\text {max }}: \mathrm{kN} / \mathrm{m}^{3}$ & $15 \cdot 4$ \\
Mean particle diameter, $D_{50}: \mathrm{mm}$ & $14 \cdot 1$ \\
Maximum particle diameter, $D_{\max }: \mathrm{mm}$ & $25 \cdot 4$ \\
Minimum particle diameter, $D_{\min }: \mathrm{mm}$ & $1 \cdot 68$ \\
Angle of repose, $\theta$ : degrees & 47 \\
Dynamic internal friction angle, $\phi:$ degrees & 43 \\
Interface basal friction angle, $\delta_{1}:$ degrees & 25 \\
Interface friction angle of retaining wall, $\delta_{2}:$ degrees & 21 \\
Interface friction angle of side wall, $\delta_{3}:$ degrees & 15 \\
\hline
\end{tabular}

the angle of repose $\left(47^{\circ}\right)$ was first measured by the tilting box method (Burkalow, 1945), which is equal to the static internal friction angle (Miura et al., 1997). It is known the dynamic friction angle is about $4^{\circ}$ less than the static internal friction angle (Hungr \& Morgenstern, 1984), so the dynamic internal friction angle was determined to be $43^{\circ}$.

An experimental flume with a frictional base was designed to reproduce granular flow in the laboratory, as shown in Fig. 3(a). The experiment considered a granular mass that began flowing from upstream of the flume at a distance of $2.19 \mathrm{~m}$ from the wall with an inclination angle of $\alpha$. Downstream of the flume, two high-speed cameras were positioned to measure the surface velocity and record movement of the granular flow. A retaining wall was divided into six segments and instrumented by six bendingbeam load cells. Each of the cells was designed to measure the normal and tangential sub-forces $\left(F_{i}\right.$ and $\left.T_{i}, i=1-6\right)$ exerted on the wall, as shown in Fig. 3(b).

The notation used to designate each experiment was based on the length $L$ and height $H$ of the initial deposit and the slope angle $\alpha$. For instance, particle 1-L44-H20- $\alpha 45$ denotes the experiment using particle 1 with an initial deposit length of $0.44 \mathrm{~m}$, a deposit height of $0.2 \mathrm{~m}$ and a slope angle of $45^{\circ}$. The experiments were conducted using different values of $L(0.14 \mathrm{~m}, 0.24 \mathrm{~m}, 0.34 \mathrm{~m}$ and $0.44 \mathrm{~m})$ and $H(0.05 \mathrm{~m}, 0.10 \mathrm{~m}, 0.15 \mathrm{~m}$ and $0.20 \mathrm{~m})$. The slope angle $\alpha$ was also varied $\left(30^{\circ}, 35^{\circ}, 40^{\circ}\right.$ and $\left.45^{\circ}\right)$. In total, $4 \times$ $4 \times 4=64$ experimental trials were performed.

\section{RESULTS AND DISCUSSION}

\section{Normal force and shear force components}

For each impact experiment, from the bottom to the top of the wall, the normal and tangential sub-forces $\left(F_{1}\right.$ to $F_{6}$ and $T_{1}$ to $T_{6}$ ) were measured. The force histories of the experiments designated particle $1-\mathrm{L} 44-\mathrm{H} 20-\alpha 45$ and particle 1-L44-H20- $\alpha 30$ are shown in Figs 4(a) and 4(b), respectively; the upper and lower plots respectively depict the history of the normal and tangential sub-forces. As indicated in Fig. 3, the normal force is referred to as positive when acting towards the face of the retaining wall and the tangential force was assigned as positive when acting in the 'upward' direction of the wall. In both Figs 4(a) and 4(b), it is interesting that, compared with the normal sub-forces, the tangential sub-forces first increase positively and subsequently increase negatively with respect to the retaining wall. Based on the captured motion images, this direction change of the tangential sub-forces can be interpreted as a change in the impact state over time, as shown in Fig. 5. In Fig. 5(a), a thick layer of particles is moving atop a relatively small stagnant zone, directly impacting the retaining wall, and deflecting upward relative to the wall. The upward deflection of the flow layer generates an upward friction on the wall, which explains the positive tangential sub-forces. During the 


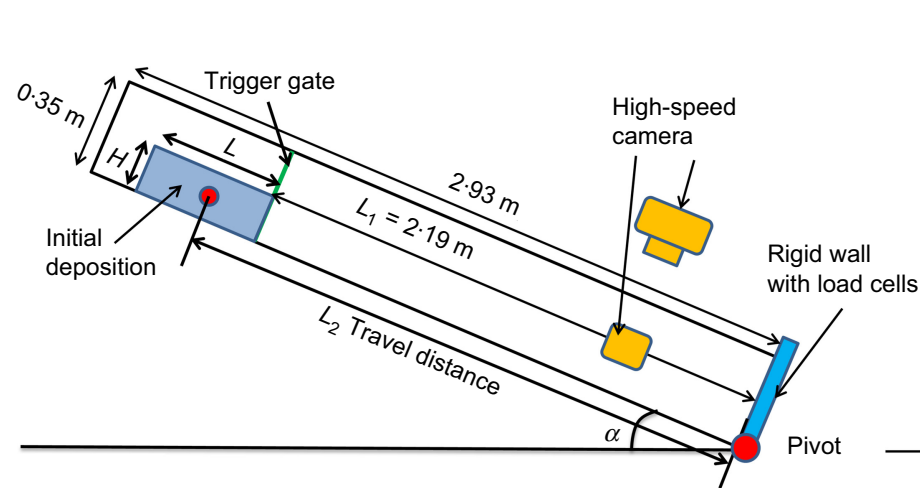

(a)

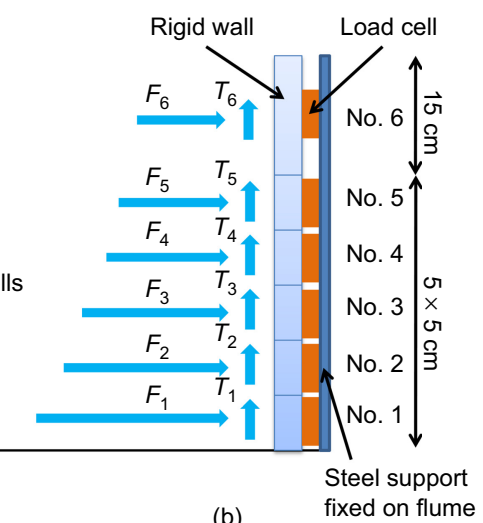

(b)

Fig. 3. Experimental flume and retaining wall setup

impact process, more granular material is deposited to form the stagnant zone and, subsequently, the granular flow layer does not directly impact the wall; the friction on the wall is mainly generated by the downward-acting gravity of the stagnant zone, which explains the negative tangential sub-forces.

For analysis purposes, the total normal force $F$ and total tangential force $T$ were first obtained by summing the normal sub-forces and the tangential sub-forces, respectively. A critical time is defined as the time when the maximum $F$ is measured, and the total normal and tangential forces at this instant are defined as $F_{\text {cr }}$ and $T_{\text {cr. }}$. Figures 6(a) and 6(b) illustrate the history of the $F$ and $T$ values of experiments. From the figures, it is obvious that the critical time for particle 1-L44-H20- $\alpha 30$ is closer to the end of the impact, and its $T_{\mathrm{cr}}$ is negative. In contrast, for particle $1-\mathrm{L} 44-\mathrm{H} 20-\alpha 45$, the critical time is closer to the middle of the impact, and both $F_{\mathrm{cr}}$ and $T_{\mathrm{cr}}$ are positive. The two critical times in Figs 6(a) and 6(b) correspond to the two different impact states shown in Figs 5(a) and 5(b), respectively, and the figures indicate that $T_{\mathrm{cr}}$ in the two experiments acts in different directions.

Values of $F_{\mathrm{cr}}$ and $T_{\mathrm{cr}}$ were deduced for all 64 experiments and thereafter the equivalent interface friction angle $\left(\delta_{\text {equi }}\right)$ was calculated by the arc tangent of $T_{\mathrm{cr}} / F_{\mathrm{cr}}$. Since positive and negative values of $\delta_{\text {equi }}$ respectively indicate the upward and downward directions of the tangential force

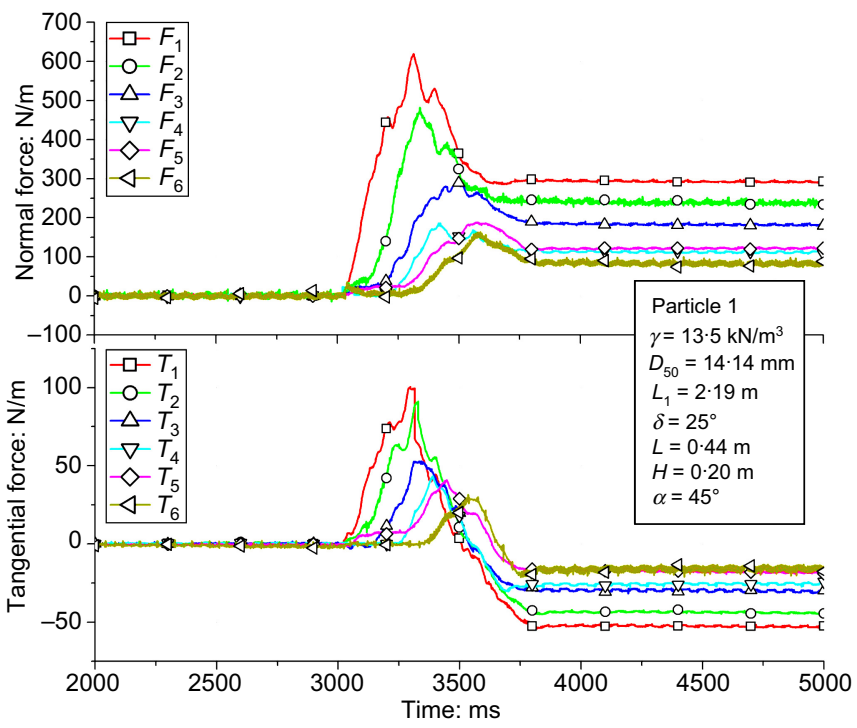

(a) with respect to the wall, Fig. 7(a) shows the change of direction of tangential force with slope angle. It is clear that the number of $\delta_{\text {equi }}$ values in the downward direction decreases with an increase in $\alpha$. This result indicates that, for smaller slope angles, the impact at the critical time tends to the state shown in Fig. 5(b) while, for greater slope angles, the impact state tends to that shown in Fig. 5(a).

The aim of Fig. 7(b) is to show the value of $\delta_{\text {equi }}$ with no concern for direction; therefore, the absolute value is used. It is interesting that the absolute $\delta_{\text {equi }}$ is always smaller than the interface friction angle $\left(\delta_{2}\right)$ measured by the interface friction test. From Fig. 7(b) it is clear that the maximum absolute value of $\delta_{\text {equi }}$ is approximately $14^{\circ}$ and the minimum is close to $0^{\circ}$ : the maximum value is considerably smaller than the measured $\delta_{2}$ value of $21^{\circ}$ (Table 1 ). In other words, $\delta_{\text {equi }}$ varies in the impact process and the measured $\delta_{2}$ cannot be used in equation (1) for force calculation. It is also interesting to observe in Fig. 7(b) that the absolute values of $\delta_{\text {equi }}$ decrease with increasing $\alpha$ (i.e. $\delta_{\text {equi }}$ is greater for smaller slope angles).

\section{Influence of interface friction angle on normal force calculation}

The above analysis shows that the actual equivalent interface friction angle is smaller than the measured interface friction angle. Therefore, it is necessary to evaluate the effect 


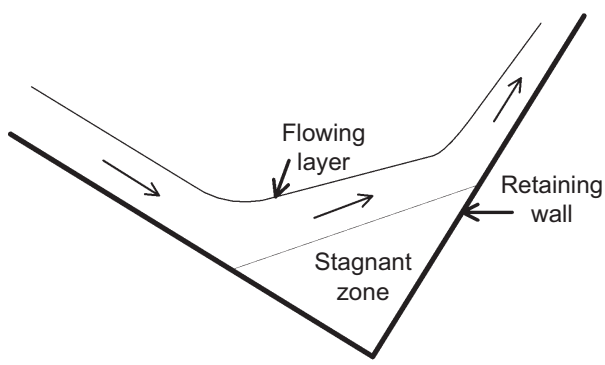

(a)

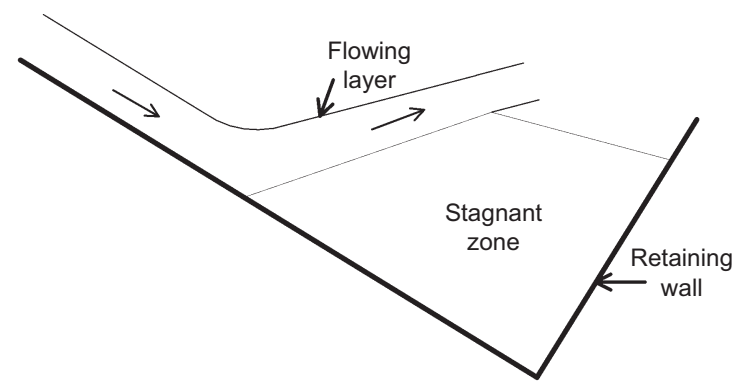

(b)

Fig. 5. Two impact states in granular flow impact

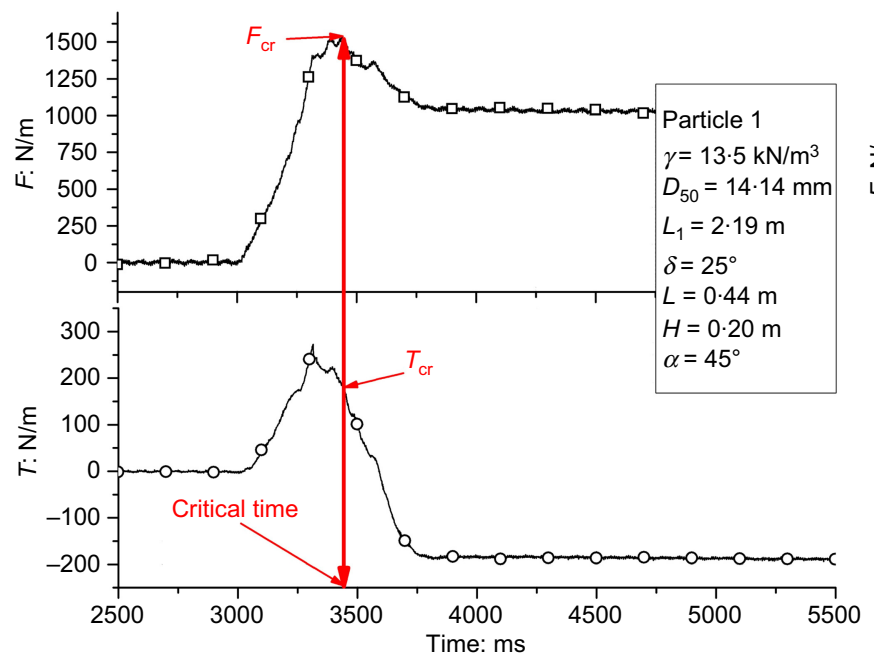

(a)

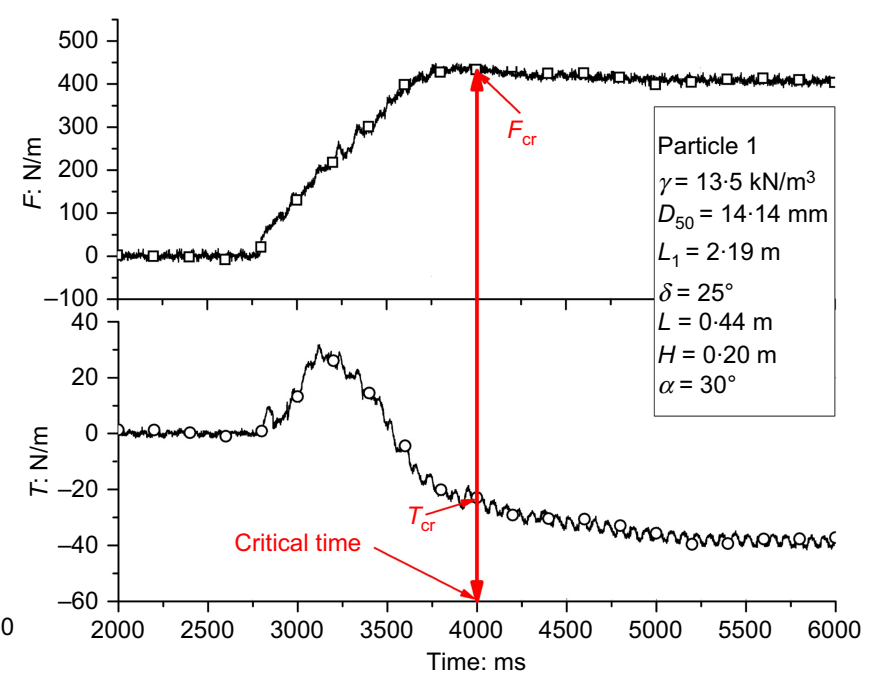

(b)

Fig. 6. History of total normal and tangential forces: (a) particle 1-L44-H20- $\alpha 45$; (b) particle 1-L44-H20- $\alpha 30$

of the interface friction angle on the calculation of the normal force using equation (1). First of all, for each experiment, the volume of the stagnant zone, the flow thickness and the velocity at the critical time were measured following the procedure of Jiang et al. (2015). Thereafter, the total normal force at the critical time was calculated and designated as $F_{\text {sum }}$ by using equation (1) and four different sets of $\delta_{1}$ and $\delta_{2}$. As a basis for comparison, $\delta_{1}=25^{\circ}$ and $\delta_{2}=21^{\circ}$ were firstly used in equation (1) and the calculated $F_{\text {sum }}$ were compared with the measured $F_{\text {cr }}$ values, as shown in Fig. 8(a). Figure 8(a) shows that $F_{\text {sum }}$ is still quite close to $F_{\text {cr }}$, with a deviation of $+30 \%$ to $-30 \%$, even though we

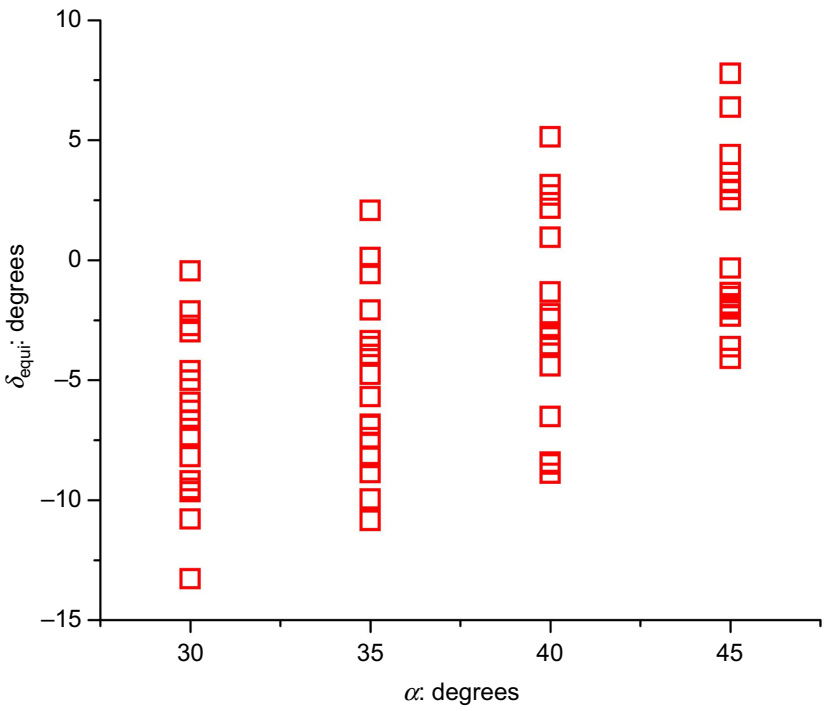

(a)

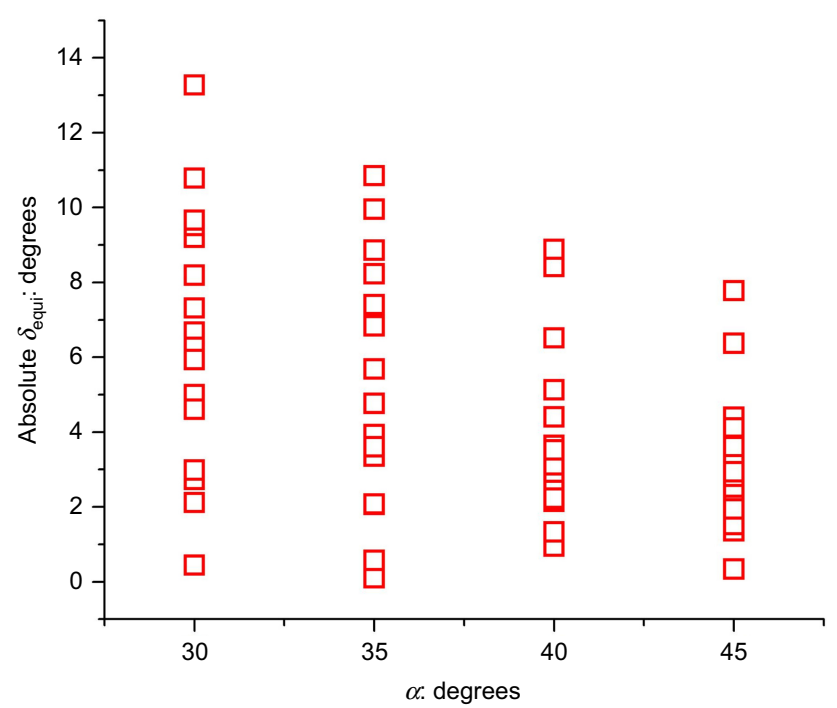

(b)

Fig. 7. Variation in $\delta_{\text {equi }}(\mathrm{a})$ and absolute $\delta_{\text {equi }}$ (b) with slope angle in the 64 experiments 


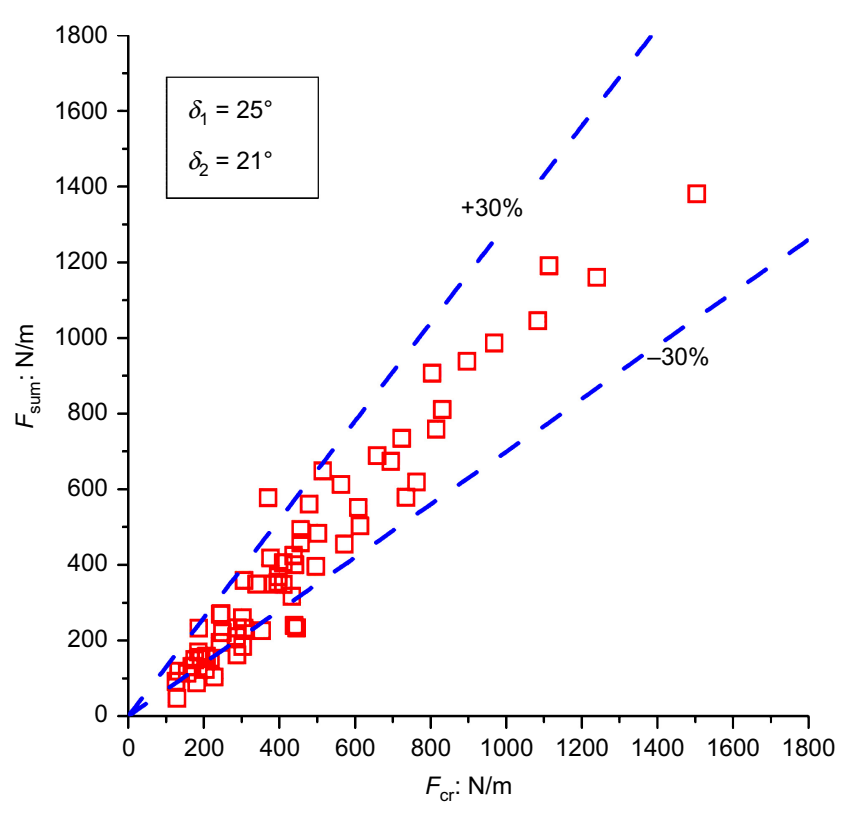

(a)

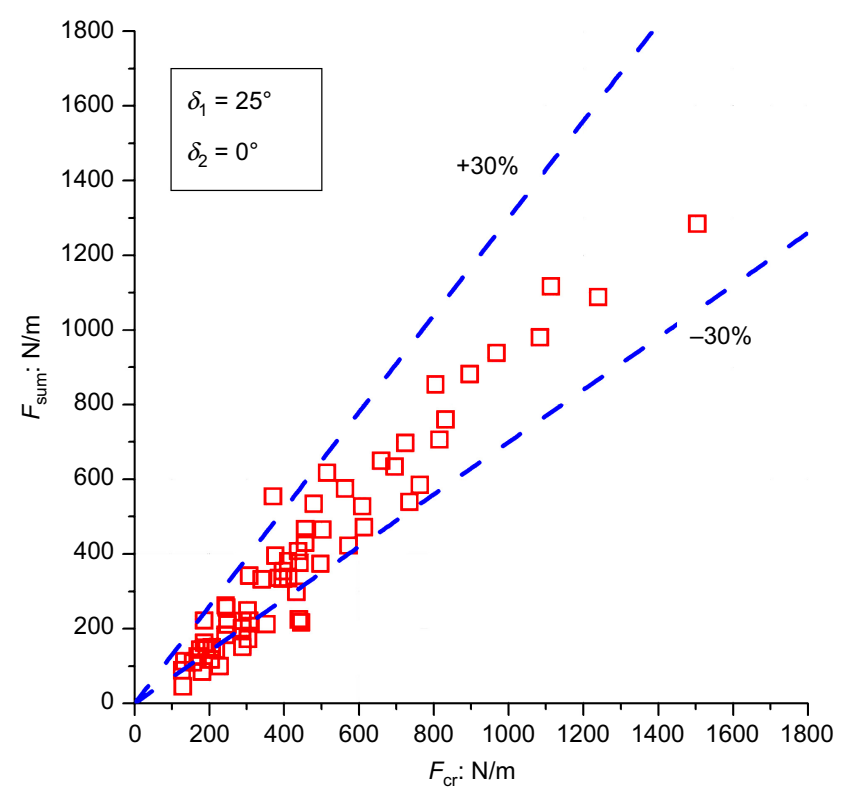

(c)

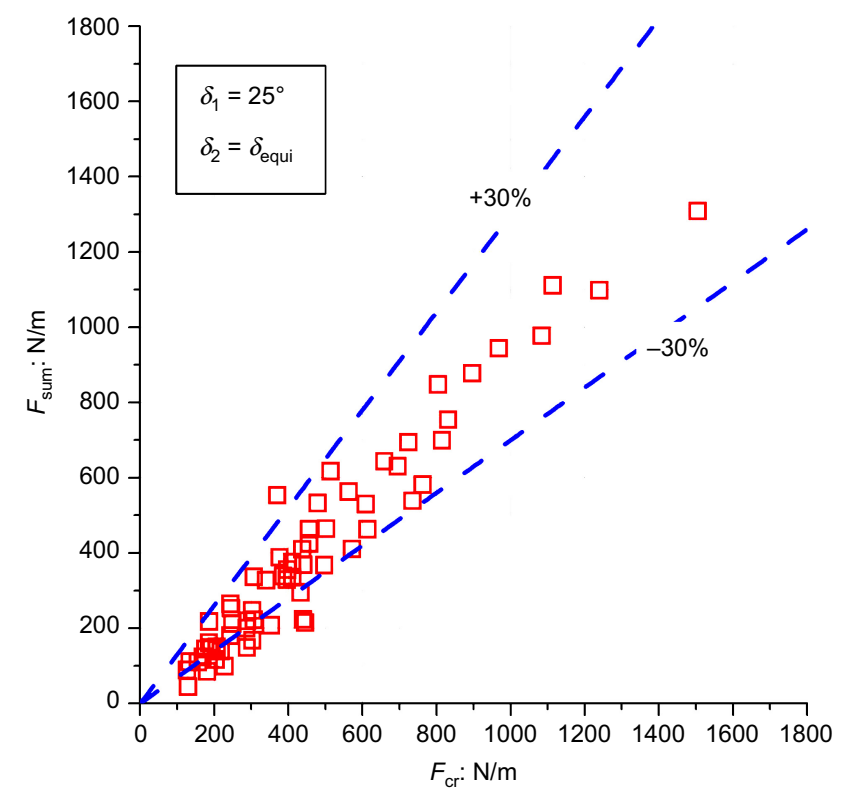

(b)

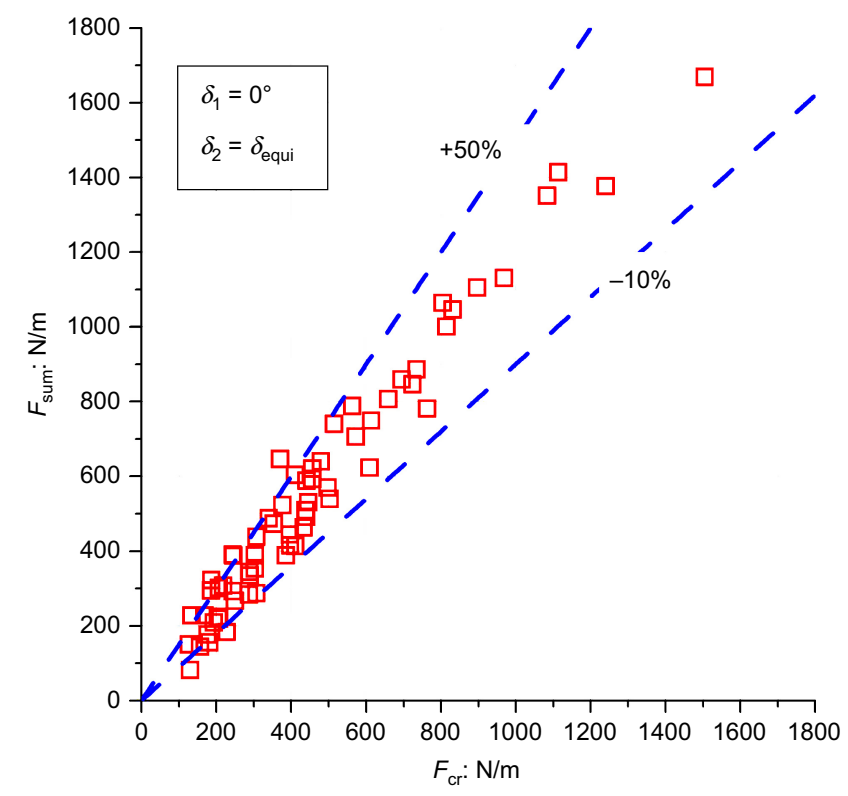

(d)

Fig. 8. Influence of interface friction between granular material and wall on total normal force calculation compared with the 64 experimental measurements

know the used $\delta_{2}$ determined from the interface friction test is overestimated compared with its actual value $\left(\delta_{\text {equi }}\right)$. When $\delta_{2}=\delta_{\text {equi }}$ (Fig. 8(b)), the result is not significantly different to the case shown in Fig. 8(a). In order to examine the limit of influence of $\delta_{2}, \delta_{2}$ was set to $0^{\circ}$ (Fig. 8(c)); this still had a negligible influence on the calculation of $F_{\text {sum. }}$. Thus, reducing $\delta_{2}$ negligibly influences $F_{\text {sum }}$ (Figs 8(a) to 8(c)). Finally, in order to examine the limiting influence of $\delta_{1}$ on $F_{\text {sum }}, \delta_{1}$ was set to $0^{\circ}$. Figure $8(\mathrm{~d})$ shows that a reduction in $\delta_{1}$ leads to a significant overestimation of $F_{\text {sum }}$, with a $+50 \%$ to $-10 \%$ deviation from the measured $F_{\mathrm{cr}}$.

\section{CONCLUSIONS}

The impact of granular flow on a retaining wall was investigated via both normal and tangential sub-force measurements. The following conclusions may be drawn from this study.
- In one granular flow impact process, the tangential subforces changed from positive to negative values, which could be interpreted as a transition between two impact states associated with the development of a stagnant zone of material at the base of the retaining wall (Fig. 5).

- In the impact process, the actual equivalent interface friction between the granular material and the wall varies, and is smaller than the value measured in interface friction tests.

- The absolute value of the equivalent interface friction angle $\left(\delta_{\text {equi }}\right)$ decreases with $\alpha$ (i.e. the equivalent friction angle is greater for smaller slope angles).

- For potential designers, an important outcome is that a reduction in the interface friction angle of the retaining wall $\left(\delta_{2}\right)$ does not much affect the outcome of $F_{\text {sum }}$, while a reduction in the interface basal friction angle $\left(\delta_{1}\right)$ 
can produce a significant overestimation of $F_{\text {sum }}$, with a $+50 \%$ to $-10 \%$ deviation from the measured $F_{\text {cr. }}$.

It is hoped that these findings will contribute to significant developments in granular flow studies.

\section{ACKNOWLEDGEMENTS}

The authors express their sincere gratitude for support from the National Natural Science Foundation of China (grant 41030742) and the Hundred Young Talents Program of the Institute of Mountain Hazards and Environment (grant SDSQB-2013-01). The support of the West Light Foundation of Chinese Academy of Sciences and the Science Foundation of the Institute of Mountain Hazards and Environment for Young Scholars is also gratefully acknowledged.

\section{REFERENCES}

Buchholtz, V. \& Pöschel, T. (1998). Interaction of a granular stream with an obstacle. Granul. Matter 1, No. 33, 33-41.

Burkalow, A. (1945). Angle of repose and angle of sliding friction: an experimental study. Geol. Soc. Am. Bull. 56, No. 6, 669-707.

Faug, T., Beguin, R. \& Chanut, B. (2009). Mean steady granular force on a wall overflowed by free-surface gravity-driven dense flows. Phys. Rev. E 80, No. 2, Part 1, 021305.

Faug, T., Caccamo, P. \& Chanut, B. (2011). Equation for the force experienced by a wall overflowed by a granular avalanche: experimental verification. Phys. Rev. E 84, No. 5, Part 1, 051301.

Hungr, O. \& Morgenstern, N. R. (1984). Experiments on the flow behavior of granular materials at high velocity in an open channel flow. Géotechnique 34, No. 3, 405-413.

Jiang, Y.-J. \& Towhata, I. (2013). Experimental study of dry granular flow and impact behavior against a rigid retaining wall. Rock Mech. Rock Engng 46, No. 4, 713-729.

Jiang, Y.-J., Zhao, Y., Towhata, I. \& Liu, D.-X. (2015). Influence of particle characteristics on impact event of dry granular flow. Powder Technol. 270, Part A, 53-67.

Miura, K., Maeda, K. \& Toki, S. (1997). Method of measurement for the angle of repose of sands. Soils and Found. 37, No. 2, 89-96.

Pudasaini, S. P., Hutter, K., Hsiau, S.-S., Tai, S.-C., Wang, Y. \& Katzenbach, R. (2007). Rapid flow of dry granular materials down inclined chutes impinging on rigid walls. Phys. Fluids 19, No. 5, 053302.

Savage, S. B. \& Hutter, K. (1989). The motion of a finite mass of granular material down a rough incline. J. Fluid Mech. 199, $177-215$.

Sovilla, B., Schaer, M., Kern, M. \& Bartelt, P. (2008). Impact pressures and flow regimes in dense snow avalanches observed at the Vallée de la Sionne test site. J. Geophys. Res. 113, No. 1, F01010.

Tai, Y. C., Gray, J. M. N. T., Hutter, K. \& Noelle, S. (2001). Flow of dense avalanches past obstructions. Ann. Glaciol. 32, No. 1, 281-284.

Thibert, E., Baroudi, D., Limam, A. \& Berthet-Rambaud, P. (2008). Avalanche impact pressure on an instrumented structure. Cold Reg. Sci. Technol. 54, No. 3, 206-215.

\section{WHAT DO YOU THINK?}

To discuss this paper, please email up to 500 words to the editor at journals@ice.org.uk. Your contribution will be forwarded to the author(s) for a reply and, if considered appropriate by the editorial panel, will be published as a discussion. 